\title{
Avaliação de linhagens e cultivares de feijão-caupi, em Areia, PB
}

\author{
Ademar P. de Oliveira ${ }^{1}$; José Tavares Sobrinho' ${ }^{1}$; João T. Nascimento ${ }^{1}$; Adriana U. Alves ${ }^{1}$; Ivanildo C. de \\ Albuquerque ${ }^{2}$; Genildo B. Bruno ${ }^{1}$. \\ ${ }^{1}$ UFPB, C. postal 02, 58.397-000, Areia-PB; ${ }^{2}$ EMEPA. 58.119-000, Lagoa Seca-PB; E-mail: ademar@cca.ufpb.br;
}

\section{RESUMO}

Dez linhagens e três cultivares de feijão-caupi foram avaliadas em ensaio conduzido em Areia (PB), de abril a julho de 2000, em Latossolo Vermelho-Amarelo. As linhagens TE-92-199-20F;TE-90170-29F; TE-90-170-76F; CNCX-405-17F; CNCX-409-12F; TE90-180-10F; TE 87-108-6G, Linhagem avançada e as cultivares, IPA 206 e BR-03 Tracuateua, apresentaram comprimento e peso médio de vagens dentro dos padrões comerciais e número médio de vagens por planta dentro do padrão para a espécie (acima de vinte vagens). A produtividade de vagens verdes e de grãos verdes e secos obtida pelas linhagens TE-90-170-76F; CNCX-409-12F; CNCX-405-17F; TE-90-180-10F; TE-87-108-6G, Linhagem avançada e pela cultivar IPA 206, foram superiores a 5,0 t/ha para vagens verdes, a 3,0 $\mathrm{t} /$ ha para grãos verdes e a 1,2 t/ha para grãos secos, consideradas altas para o feijão-caupi. As maiores produtividade de vagens verdes $(6,5$ e $6,5 \mathrm{t} / \mathrm{ha})$, de grãos verdes ( 3,8 e $3,8 \mathrm{t} / \mathrm{ha})$, e de grãos secos $(1,8 \mathrm{e}$ $1,8 \mathrm{t} / \mathrm{ha}$ ) foram obtidas, respectivamente, com as linhagem CNCX409-12F e cultivar IPA 206.

Palavras-chave: Vigna unguiculata, vagens, grãos verdes, grãos secos, rendimento.

\begin{abstract}
Evaluation of breeding lines and cultivars of cowpea-beans in Areia, Paraiba, Brazil

Ten breeding lines and three cultivars of cowpea-bean were evaluated. The experiment was set up in Areia, Brazil, between April and July/00, in Red-yellow Latossoil. The breeding lines TE-92199-20F; TE-90-170-29F; TE-90-170-76F; CNCX-405-17F; CNCX409-12F; TE-90-180-10F; TE-87-108-6G, Linhagem avançada, and IPA 206, BR-03 Tracuateua, cvs., presented length and average weight of pods according to the commercial patterns and number of pods by plant according to the pattern of the species (above twenty pods). The yield of green pods, green and dry grains, obtained by the breeding lines TE-90-170-76F; CNCX-409-12F; CNC-405-17F; TE-90-180-0F; TE-87-108-6G, Linhagem avançada and IPA 206, cultivar, were superior to $5.0 \mathrm{t} / \mathrm{ha}$ for green pods, to $3.0 \mathrm{t} / \mathrm{ha}$ for green grains and to $1.2 \mathrm{t} / \mathrm{ha}$ for dry grains, considered highest for the cowpea-beans. Highest yield of green pods ( 6.5 and $6.5 \mathrm{t} / \mathrm{ha}$ ), green grains (3.8 and $3.8 \mathrm{t} / \mathrm{ha})$, and dry grains (1.8 and $1.8 \mathrm{t} / \mathrm{ha})$ were obtained, respectively, with the breeding line CNCX-409-12F and IPA $206 \mathrm{cv}$.
\end{abstract}

Keywords: Vigna unguiculata, pods, green grains, dry grains, yield.

\section{(Aceito para publicação em 15 de fevereiro de 2.002)}

$\mathrm{O}$ feijão-caupi, conhecido no Nordeste brasileiro por feijãomacassar ou feijão-de-corda, é uma das principais culturas desta região, sendo considerado fonte de renda alternativa e alimento básico para sua população. É consumido sob as formas de grãos secos e verdes, além de seus caules e ramos serem usualmente utilizados na alimentação animal (Silva \& Oliveira, 1993). Além disso, por sua capacidade de se desenvolver satisfatoriamente em solos de baixa fertilidade e por sua rusticidade, o feijão-caupi é considerado uma opção como fonte de matéria orgânica. Nessa forma, é utilizado como adubo verde na recuperação de solos naturalmente pobres em fertilidade, ou esgotados pelo uso intensivo, muito comum no Nordeste (Oliveira \& Carvalho, 1988).

No estado da Paraíba, o feijão-caupi é cultivado em quase todas as microregiões, onde detém $75 \%$ das áreas de cultivo com feijão. Assim, exerce efetiva participação na dieta alimentar da população, por constituir-se em excelente fonte de proteínas e carboidratos de baixo custo (Silva \& Oliveira, 1993; IBGE,1996). Embora considerada uma cultura tropical, compatível com as condições ecológicas locais, ainda apresenta baixa produtividade, tanto no sistema solteiro como no consorciado (Miranda et al., 1996). Dentre as principais causas que limitam a produtividade do feijão-caupi no Nordeste, merece destaque o emprego de cultivares tradicionais com baixa capacidade produtiva (Aquino \& Nunes, 1983), razão pela qual Maia et al. (1986) admitem que o aumento de produtividade pode ser alcançado mediante a simples utilização de sementes de qualidade superior. Contudo, mesmo utilizando sementes de boa qualidade, se a cultivar for de baixo potencial genético para a produção, será baixo o rendimento. Um dos problemas associado à baixa produtividade, pode estar relacionado ao fato de que geralmente são utilizadas as mesmas cultivares tanto para produção de grãos verdes, quanto para grãos secos.

No mercado brasileiro existem cultivares de boa aceitação comercial. Entretanto, não há um programa nacional que vise a avaliação e recomendação de cultivares em ambientes específicos. Estudos sobre novas opções de cultivares são necessários, pois, geralmente, o produtor tem utilizado, por conta e risco, qualquer semente disponível no mercado fazendo testes empíricos para escolha de cultivares levando a muitas frustrações. A indicação de cultivares apropriadas proporcionaria maior segurança ao produtor, facilitando a obtenção de crédito e aceitação do produto no mercado.

Os trabalhos de melhoramento de feijão-caupi no Brasil são escassos e as cultivares disponíveis estão sendo utili- 
zadas sem se considerar as suas possíveis diferenças de comportamento nas diversas regiões de cultivo. É importante que se façam estudos regionais visando selecionar genótipos superiores tanto para cultivo como para uso em programas de melhoramento genético.

Devido a existência de fatores que interferem na produção do feijão-caupi, Barriga \& Oliveira (1982) e Freire Filho (1988), observaram que o rendimento de grãos secos pode não ser o melhor critério para a seleção de cultivares superiores. Assim sendo, sugeriram que a seleção seja feita também em função de outros componentes de produção, tais como o número de vagens por planta e as produções de vagens e de grãos verdes.

O trabalho teve como objetivo avaliar o comportamento de dez linhagens e três cultivares de feijão-caupi, quanto à produção de vagens verdes, grãos verdes e secos nas condições edafoclimáticas do município de Areia (PB).

\section{MATERIAL E MÉTODOS}

O trabalho foi conduzido na área experimental da UFPB, em Areia (PB), em Latossolo Vermelho-Amarelo, no período de abril a julho de 2000. A temperatura média em ${ }^{\circ} \mathrm{C}$, a precipitação pluviométrica em mm e a umidade relativa em $\%$ do período foram, respectivamente: abril $=4,9 ; 24$ e 73,7; maio $=$ 22,$5 ; 125,5$ e 80,$2 ;$ junho $=21,2 ; 137,8$ e 81,74 ; julho $=21,86 ; 193,30$ e 82,57.

A análise química das amostras do solo utilizado revelou: $\mathrm{pH} \mathrm{H}_{2} \mathrm{O}=6,90$; $\mathrm{P}$ disponível $=156,00 \mathrm{mg} / \mathrm{dm}^{3} ; \mathrm{K}=$ 95,$00 ; \mathrm{mg} / \mathrm{dm}^{3} ; \mathrm{Al}$ trocável $=0,0 \mathrm{cmol}_{\mathrm{c}} /$ $\mathrm{dm}^{3} ; \mathrm{Ca}^{+2}+\mathrm{Mg}=4,75 ; \mathrm{cmol}_{\mathrm{c}} / \mathrm{dm}^{3} \mathrm{e}$ matéria orgânica $=11,3 \mathrm{~g} / \mathrm{dm}^{3}$.

Foram avaliadas dez linhagens (TE92-199-20F; TE-90-170-29F; TE-90170-76F; CNCX-405-17F; CNCX-40912F; TE-90-180-10F; TE-87-108-6G; TE-90-180-9F; TE-90-180-88F e Linhagem avançada) provenientes da EMEPA (PB) e as cultivares comerciais IPA 206, BR-02 Bragança e BR-03 Tracuateua. Todas as linhagens e cultivares tinham hábito de crescimento semi-ramador.

As plantas foram dispostas em quatro fileiras, no espaçamento de $1,00 \mathrm{x}$ $0,50 \mathrm{~m}$, em parcelas com 40 plantas, sendo consideradas úteis as duas filei- ras centrais, uma para avaliações de vagens e de grãos verdes e a outra para avaliação de grãos secos. O delineamento experimental utilizado foi o de blocos casualizados com treze tratamentos em quatro repetições.

O preparo do solo constou de aração, gradagem e sulcamento com tração mecânica e marcação de covas com auxílio de enxada. Foram feitas adubações de plantio à base de $20 \mathrm{t} /$ ha de esterco bovino curtido e seco, $300 \mathrm{~kg} /$ ha de superfosfato simples e $170 \mathrm{~kg} /$ ha de cloreto de potássio. Em cobertura aplicou-se $300 \mathrm{~kg} /$ ha de sulfato de amônio, $50 \%$ aos 20 e $50 \%$ aos 40 dias após a semeadura.

No plantio utilizaram-se quatro sementes por cova, realizando-se o desbaste quinze dias depois, deixando-se uma planta. Durante a condução da cultura foram realizadas pulverizações à base de deltametrina 2,5E, para combater a cigarrinha do feijoeiro (Empoasca krameari).

Realizaram-se os tratos culturais normais para a cultura, incluindo irrigação por aspersão, procurando fornecer quantidade de água suficiente para o bom desenvolvimento da cultura, além de capinas com auxílio de enxadas para manter sempre a cultura livre de plantas invasoras.

Foram feitas seis colheitas, obtendose inicialmente dados de número de vagens por planta e de produtividades de vagens verdes (no estádio que permitisse a debulha manual para a obtenção de grãos verdes), de grãos verdes (com aproximadamente 60 a $70 \%$ de umidade) e de grãos secos (com teor de umidade em torno de 13\%). Como características de qualidade de vagens foram avaliados o comprimento (média de 20 vagens por tratamento, em cada colheita) e peso médio das vagens verdes (relação entre a produção e o número de vagens colhidas). Procedeu-se à análise de variância, comparando-se as médias das características avaliadas pelo teste de Tukey ao nível de $5 \%$ de probabilidade.

\section{RESULTADOS E DISCUSSÃO}

Obtiveram-se diferenças estatisticamente significativas entre os genótipos para todas as características estudadas (Tabela 1).
Com exceção das linhagens TE-90180-9F; TE-90-180-88F e da cultivar BR-02 Bragança, os valores obtidos para o comprimento e peso médio de vagens situaram-se dentro dos padrões comerciais, de acordo com o estabelecido por Pereira et al. (1992), Silva \& Oliveira (1993) e Miranda et al. (1996), acima de $20 \mathrm{~cm}$ para o comprimento e acima de $14 \mathrm{~g}$ para o peso de vagens. A linhagem CNCX-409-12F e a cultivar IPA 206, apresentaram os mais elevados valores para o comprimento das vagens, porém não diferiram significativamente das linhagens TE-90-180-10F; TE-87108-6G e Linhagem avançada e da cultivar BR-03- Tracuateua. Para o peso médio de vagens, a linhagem CNCX-409$12 \mathrm{~F}$ e a cultivar IPA 206, diferiram significativamente apenas das linhagens TE90-180-9F e TE-90-180-88F (Tabela 1).

Todos os genótipos, exceto as linhagens TE-90-180-9F e TE-90-188-88F, apresentaram número de vagens por planta dentro do padrão para a espécie, acima de vinte vagens (Silva \& Oliveira, 1993; Miranda et al., 1996; Silva \& Freitas, 1996). Apesar da linhagem CNCX-409-12F e da cultivar IPA 206, apresentarem os maiores números de vagens/planta, não diferiram estatisticamente da linhagem TE-87-108-6G e da cultivar BR-03 Tracuateua, enquanto que as linhagens TE-92-199-20F; TE-90170-76F; TE-90-180-9F; TE-90-180$88 \mathrm{~F}$ e a cultivar BR-02 Bragança, embora tenham produzidos os menores números de vagens por planta, não diferiram estatisticamente das linhagens CNCX405-17F; TE-90-180-10F; TE-87-1086G e Linhagem avançada (Tabela 1).

As produtividades de vagens verdes, de grãos verdes e de grãos secos obtidas pelas linhagens TE-90-170-76F; CNCX-409-12F; CNCX-405-17F; TE90-180-10F, Linhagem avançada, TE87-108-6G e pela cultivar IPA 206 foram superiores a 5,0 t/ha para vagens verdes, a 3,0 t/ha para grãos verdes e a $1,2 \mathrm{t} /$ ha para grãos secos, consideradas altas para o feijão-caupi, conforme Silva \& Oliveira (1993), Miranda et al. (1996) e Silva \& Freitas (1996). A linhagem CNCX-409-12F e a cultivar IPA 206, apresentaram as maiores produtividades de vagens verdes, de grãos verdes e de grãos secos e o maior nú- 
Tabela 1. Valores médios de comprimento, peso médio de vagens, número de vagens/planta, rendimentos médios de vagens verdes, de grãos verdes e de grãos secos de genótipos de feijão-caupi. Areia, UFPB, 2000.

\begin{tabular}{|c|c|c|c|c|c|c|}
\hline Genótipos & $\begin{array}{l}\text { Comprimento } \\
\text { (cm) }\end{array}$ & $\begin{array}{l}\text { Peso médio } \\
\text { (g) }\end{array}$ & $\begin{array}{c}\text { Número de } \\
\text { vagens/planta }\end{array}$ & $\begin{array}{c}\text { Vagens } \\
\text { verdes } \\
(t / h a)\end{array}$ & $\begin{array}{c}\text { Grãos } \\
\text { verdes } \\
\text { (t/ha) }\end{array}$ & $\begin{array}{l}\text { Grãos } \\
\text { secos } \\
\text { (t/ha) }\end{array}$ \\
\hline TE-92-199-20F & 23,0 bcd & $15,0 \mathrm{ab}$ & 21,0 & $4,2 a b c$ & $3,0 a b$ & $1,3 \mathrm{ab}$ \\
\hline TE-90-170-29F & $23,0 \mathrm{bcd}$ & $15,0 a b$ & 21,0 & $4,1 \mathrm{abc}$ & $2,8 a b$ & $1,1 a b$ \\
\hline TE-90-170-76F & $22,0 \mathrm{bcd}$ & $15,0 a b$ & 21,0 & $5,8 a b$ & $3,8 a b$ & $1,3 a b$ \\
\hline CNCX-405-17F & 22,0 cde & $15,0 \mathrm{abc}$ & $23,0 \quad b c$ & $5,1 \mathrm{abc}$ & $3,2 a b$ & $1,3 a b$ \\
\hline CNCX-409-12F & $26,0 \mathrm{a}$ & $17,0 \mathrm{a}$ & $29,0 \mathrm{a}$ & $6,5 \mathrm{a}$ & $3,8 \mathrm{a}$ & $1,8 \mathrm{a}$ \\
\hline TE-90-180-10F & $24,0 \mathrm{abc}$ & $16,0 \mathrm{ab}$ & $22,0 \quad b c$ & $5,5 a b$ & $3,1 a b$ & $1,3 a b$ \\
\hline TE-87-108-6G & $25,0 a b$ & $16,0 a b$ & $23,0 a b c$ & $5,3 a b c$ & $3,5 a b$ & $1,5 a b$ \\
\hline TE-90-180-9F & 19,0 & $13,0 \quad b c$ & $19,0 \quad c$ & $3,6 \mathrm{bc}$ & $2,6 a b$ & $1,1 a b$ \\
\hline TE-90-180-88F & 20,0 de & $11,0 \quad c$ & $15,0 \quad c$ & $2,8 \quad c$ & $2,3 a b$ & $0,8 \quad b$ \\
\hline Linhagem avançada & $23,0 a b c$ & $16,0 a b$ & $23,0 \mathrm{bc}$ & $5,8 \mathrm{ab}$ & $3,1 a b$ & $1,3 a b$ \\
\hline IPA 206 & $26,0 \mathrm{a}$ & $16,0 \mathrm{a}$ & $29,0 \mathrm{a}$ & $6,5 \mathrm{a}$ & $3,8 \mathrm{a}$ & $1,8 \mathrm{a}$ \\
\hline BR-02 Bragança & 17,0 & $14,0 \mathrm{abc}$ & $20,0 \quad c$ & $4,5 \mathrm{abc}$ & $2,0 \mathrm{~b}$ & $0,6 \mathrm{~b}$ \\
\hline BR-03 Tracuateua & $25,0 \mathrm{ab}$ & $16,0 \mathrm{ab}$ & $25,0 \mathrm{ab}$ & $4,6 \mathrm{abc}$ & $3,3 a b$ & $1,4 a b$ \\
\hline C.V $(\%)$ & 4,4 & 12,8 & 11,2 & 21,5 & 23,5 & 29,3 \\
\hline
\end{tabular}

Média seguidas da mesma letra, na coluna, não diferem entre si pelo teste de Tukey ao nível de 5 \% de probabilidade.

mero de vagens por planta. A linhagem TE-90-180-88F apresentou a mais baixa produtividade de vagens verdes, mas não diferiu estatisticamente das linhagens TE-90-180-9F; TE-90-170-29F; TE-92-199-20F; CNCX-405-17F; TE87-108-6G e das cultivares BR-02 Bragança e BR-03 Tracuateua. A cultivar BR-02 Bragança apresentou as mais baixas produtividades de grãos verdes e secos, embora só tenha diferido estatisticamente das linhagem CNCX-40912F e da cultivar IPA 206 (Tabela 1).

Como para o produtor de hortaliças é desejável a utilização de cultivares adaptadas às suas condições edafoclimáticas, a linhagem CNCX409-12F e a cultivar IPA 206 por serem as mais produtivas entre as de melhor qualidade, podem ser indicadas como alternativas ao produtor, inclusive com maior possibilidade de lucro. As linhagens TE-90-170-76F; CNCX-405-17F; TE-90-180-10F, Linhagem avançada e TE-87-108-6G também poderão atender a esse propósito, isso porque apresentaram produtividades e características de vagens satisfatórias.

\section{AGRADECIMENTOS}

Os autores agradecem à Professora Sheila Costa de Farias pela correção do Abstract e aos agentes em Agropecuária Francisco de Castro Azevedo, José Barbosa de Souza, Francisco Soares de Brito, Francisco Silva do Nascimento e Expedito de Souza Lima que viabilizaram a execução dos trabalhos de campo.

\section{LITERATURA CITADA}

AQUINO, S.F.; NUNES, R.P. Estrutura genética de populações de caupi e suas implicações no melhoramento genético através da seleção. Pesquisa Agropecuária Brasileira, Brasília, v. 18, n. 4, p. 399-412, 1983.

BARRIGA, R.H.M.P.; OLIVEIRA, A.F.F. Viabilidade genética e correlações entre o rendimento e seus componentes em caupi (Vigna unguiculata (L.) Walp.) na região amazônica. Belém, EMBRAPA-CPATU, 1982. 16 p. (EmbrapaCPATU, boletim de pesquisa 38 ).

FREIRE FILHO, F.R. Genética do caupi. In: ARAÚJO, J.P.P.; WATT, E.E. prg. O caupi no Brasil. Brasília: IITA/EMBRAPA, 1988. p. 159 229.
IBGE. Levantamento sistemático da produção agrícola da Paraíba (LSPA-PB). Fundação Instituto Brasileiro de Geografia e Estatística-FIBGEGCEA/PB, J. Pessoa-PB, 1996.

MAIA, A.F.; ASSUNÇÃO, M.V.; ALVES, J.F. Influência do método de debulha e da umidade na produção de sementes de feijão de corda. Ciência Agronômica, Fortaleza, v. 17, n. 2, p. 91 - 100, 1986.

MIRANDA, P.; COSTA, A.F.; OLIVEIRA, L.R.; TAVARES, J.A.; PIMENTEL, M.L.; LINS, G.M.L. Comportamento de cultivares de Vigna unguiculata (L) Walp., nos sistemas solteiro e consorciado. IV - tipos ereto e semi-ereto. Pesquisa Agropecuária Pernambucana, Recife, v. 9, n. especial, p. 95-105, 1996.

OLIVEIRA, I.P.; CARVALHO, A.M. A cultura do caupi nas condições de clima e de solo dos trópicos úmidos de semi-árido do Brasil. In: ARAÚJO, J.P.P.; WATT, E.E. org. O caupi no Brasil. Brasília: IITA/EMBRAPA, 1988. p. 63-96.

PEREIRA, J.A.; BELARMINO FILHO, J.; SANTOS, J.F.; ARANHA, V.S. Caracteres agronômicos e suas correlações em linhagens de feijãomacassar. EMEPA, 1992 (Boletim de pesquisa 06).

SILVA, P.S.L.; FREITAS, C.J. Rendimentos de grãos verdes de milho e caupi em cultivos puros e consorciados. Revista Ceres, Viçosa, v. 43, n. 245, p. 28-38, 1996.

SILVA, P.S.L.; OLIVEIRA, C.N. Rendimentos de feijão verde e maduro de cultivares de caupi. Horticultura Brasileira, Brasília, v. 11, n. 2, p 133135, 1993. 